\title{
Composition and antimicrobial activities of the leaf essential oil of Machilus zuihoensis from Taiwan
}

\author{
Chen-Lung Ho, ${ }^{1,2}$ Pei-Chun Liao, ${ }^{3}$ Yu-Chang Su ${ }^{*}, 1$ \\ ${ }^{1}$ Department of Forestry, National Chung Hsing University, Taichung, Taiwan 402, \\ ${ }^{2}$ Division of Wood Cellulose, Taiwan Forestry Research Institute, Taiwan 100, \\ ${ }^{3}$ Institute of Biotechnology, National Ilan University, Taiwan 260.
}

Revista Brasileira de Farmacognosia Brazilian Journal of Pharmacognosy 22(2): 277-283, Mar./Apr. 2012
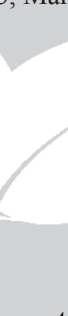

\section{Article}

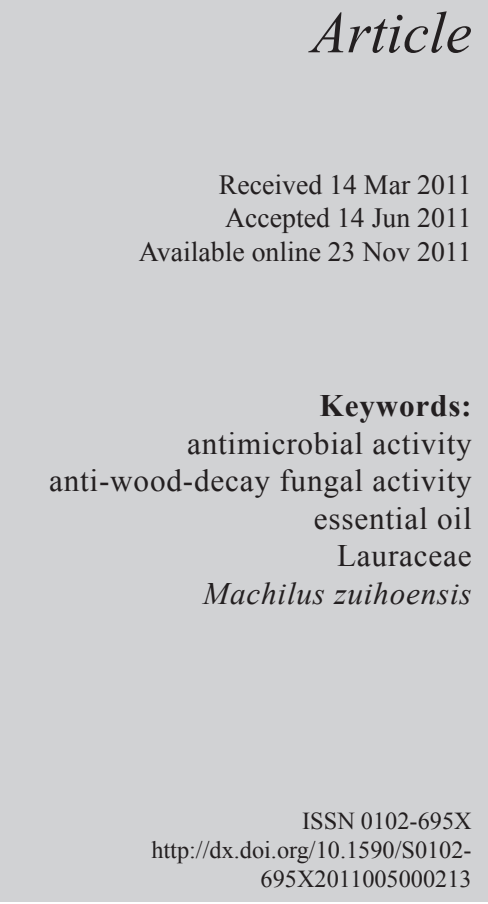

Received 14 Mar 2011 Accepted 14 Jun 2011

\begin{abstract}
This study investigated the chemical composition, and antimicrobial and anti-wood-decay fungal activities of the essential oil isolated from the leaf of endemic Machilus zuihoensis Hayata, Lauraceae, of Taiwan. The essential oil from the fresh leaves of $M$. zuihoensis was isolated using hydrodistillation in a Clevenger-type apparatus, and characterized by GC-FID and GC-MS. A total of 104 compounds were identified, representing $100 \%$ of the oil. The main components identified were $n$-dodecanal $(23.8 \%)$ and $(E)$-nerolidol $(10.5 \%)$. The antimicrobial activity of the oil was tested by the disc diffusion method and micro-broth dilution method against ten microbial species (Bacillus cereus, Staphylococcus aureus, S. epidermidis, Escherichia coli, Enterobacter aerogenes, Klebsiella pneumoniae, Pseudomonas aeruginosa, Vibrio parahaemolyticus, Aspergillus niger, and Candida albicans), respectively. The oil exhibited strong growth suppression against Grampositive bacteria and yeast with inhibition zones of $35 \sim 43 \mathrm{~mm}$ to MIC values of $125 \mu \mathrm{g} \mathrm{mL} \mathrm{m}^{-1}$, respectively. The anti-wood-decay fungal activity of the oil was also evaluated. Results showed that the oil demonstrated excellent activity against four wood-decay-fungi species (Trametes versicolor, Phaneochaete chrysosporium, Phaeolus schweintizii, and Lenzites sulphureu). For the antimicrobial and anti-wooddecay fungal activities of the oil, the active source compounds were determined to be $\tau$-cadinol, $\beta$-eudesmol, and $n$-dodecanal.
\end{abstract}

(1)


brown rot fungi in Taiwan to examine their respective interdiction efficacies. As a consequence, the second part of the study examined the antimicrobial and antiwood-decay fungal activities of the essential oils. The purpose of this study was to establish a chemical basis for effective multipurpose utilization of the species.

\section{Material and Methods}

\section{Plant material}

Fresh leaves of Machilus zuihoensis Hayata, Lauraceae, were collected in July 2010 from Tiaomikeng (Nantou County, central Taiwan, elevation $\left.1050 \mathrm{~m}, \mathrm{~N} 23^{\circ} 57^{\prime} 08^{\prime \prime}, \mathrm{E} 120^{\circ} 54^{\prime} 36^{\prime \prime}\right)$. The samples were compared with specimen no. TAIF 65078 from the Herbarium of the Taiwan Forestry Research Institute and were positively identified by Prof. Yen-Hsueh Tseng of National Chung Hsing University (NCHU). The voucher specimen (CLH-014) was deposited in the NCHU herbarium. Before extraction, the leaf was air dried at room temperature protected from the light for one week.

\section{Isolation of leaf essential oil}

The essential oil of the dry leaves (200 g) was extracted using a Clevenger-type apparatus using a hydrodistillation technique. After extraction, the volume of essential oil obtained was measured, and the essential oil was stored in glass containers hermetically sealed with rubber lids, covered with aluminum foil to protect the contents from light, and kept refrigerated at $8{ }^{\circ} \mathrm{C}$ until used. The oil yield and all test data are the average of triplicate analyses.

\section{Essential oil analysis}

A Hewlett-Packard HP 6890 gas chromatograph equipped with a DB-5 fused silica capillary column (30 $\mathrm{m} \times 0.25 \mathrm{~mm} \times 0.25 \mu \mathrm{m}$ film thickness, J\&W Scientific) and a FID detector was used for quantitatively determining oil components. Oven temperature was programmed as follows: $50{ }^{\circ} \mathrm{C}$ for $2 \mathrm{~min}$, rising to $250{ }^{\circ} \mathrm{C}$ at $5{ }^{\circ} \mathrm{C}$ min- 1 . Injector temperature: $270{ }^{\circ} \mathrm{C}$. Carrier gas: He with a flow rate of $1 \mathrm{~mL} \mathrm{~min}^{-1}$. Detector temperature: $250{ }^{\circ} \mathrm{C}$, split ratio: $1: 10$. Diluted samples $(1.0 \mu \mathrm{L}, 1 / 100, \mathrm{v} / \mathrm{v}$, in ethyl acetate) were injected manually in the split mode. Identification of the oil components was based on their retention indices and mass spectra, obtained from GC-MS analysis on a Hewlett-Packard HP 6890/HP5973 equipped with a DB-5 fused silica capillary column $(30 \mathrm{~m}$ x $0.25 \mathrm{~mm} \times$ $0.25 \mu \mathrm{m}$ film thickness, J\&W Scientific). The GC analysis parameters listed above and the MS were obtained (full scan mode: scan time: $0.3 \mathrm{~s}$, mass range was $\mathrm{m} / \mathrm{z} 30-500$ ) in the EI mode at $70 \mathrm{eV}$. All data were the average of triplicate analyses.

\section{Component identification}

Identification of the leaf essential oil constituents was based on comparisons of retention index (RI) (Adams, 2001), retention times (RT), and mass spectra with those obtained from authentic standards and/or the NIST and Wiley libraries spectra, and relevant literature (Adams, 2001; Massada, 1976).

\section{Antimicrobial activity}

The in vitro antibacterial and antimicrobial activities of the oil were evaluated by the disc diffusion method using Mueller-Hinton agar for bacteria and Sabouraud dextrose agar for fungi (Baron \& Finegold, 1990). Discs containing $15 \mu \mathrm{L}$ and $30 \mu \mathrm{L}$ of the oil, which was dissolved in dimethyl sulphoxide (DMSO), were placed on the inoculated plates with test microorganisms. Growth inhibition zones (including a disc diameter of $6 \mathrm{~mm}$ ) were measured after 24 and 48 $\mathrm{h}$ of incubation at 37 and $24^{\circ} \mathrm{C}$ for bacteria and fungi, respectively. Gentamicine and tetracycline for bacteria, and nystatine for fungi were used as positive controls.

Microbial strains were obtained from the Culture Collection and Research Center of the Food Industry Research and Development Institute, Hsinchu City, Taiwan. The microbial strains included five Gram-negative bacteria: Escherichia coli (IFO 3301), Enterobacter aerogenes (ATCC 13048), Klebsiella pneumoniae (ATCC 4352), Pseudomonas aeruginosa (IFO 3080), and Vibrio parahaemolyticus (ATCC 17803); three Gram-positive bacteria: Bacillus cereus (ATCC 11778), Staphylococcus aureus (ATCC 6538P), and S. epidermidis (ATCC 12228); one fungus: Aspergillus niger (ATCC 16404) and one yeast: Candida albicans (ATCC 10231). Minimum inhibitory concentration (MIC) values were measured by the micro-dilution broth susceptibility assay recommended by NCCLS (NCCLS, 1999). Stock solutions of the oil were prepared in DMSO. Dilution series were prepared from $1000 \mu \mathrm{g} \mathrm{mL} \mathrm{m}^{-1}$ to $50 \mu \mathrm{g} \mathrm{mL} \mathrm{mL}^{-1}$ in sterile distilled water in micro-test tubes, from where they were transferred to 96-well microtiter plates. Bacteria grown in double-strength Mueller-Hinton broth and fungi grown in double-strength Sabouraud dextrose broth were standardized to $108 \mathrm{CFU} \mathrm{mL}^{-1}$. The last row, containing only the serial dilutions of sample without microorganisms, was used as a negative control. Sterile distilled water and medium served as a positive control. After incubation at $37^{\circ} \mathrm{C}$ for $24 \mathrm{~h}$ and $24^{\circ} \mathrm{C}$ for $48 \mathrm{~h}$, the $\mathrm{MIC}$ values were determined. All experiments were performed in triplicate. 
Anti-wood-decay fungal assays

The method of Cheng et al. (2005) was adopted. The fungi used were Trametes versicolor (L. ex Fr.) Quel. (BCRC 35253), Phanerochaete chrysosporium Burdsall (BCRC 36200), Phaeolus schweinitzii (Fries) Paterson (BCRC 35365) and Lenzites sulphureu (B. ex Fr.) Bond. (BCRC 35305). Cultures of each of the fungi were maintained on potato dextrose agar (PDA) medium and were stored at $4{ }^{\circ} \mathrm{C}$. Microbial strains were obtained from the Culture Collection and Research Center of the Food Industry Research and Development Institute, Hsinchu City, Taiwan. Anti-wood-decay fungal assays were performed in triplicate and the data were averaged. Briefly, 100.0, 75.0, 50.0, 25.0 and $12.5 \mu \mathrm{g} \mathrm{mL}^{-1}$ of essential oils were added to sterilized PDA in $9 \mathrm{~cm}$ plates (Petri dish). After transfer of the mycelium of four fungi strains, the testing Petri dishes were incubated in the dark at $26 \pm 2{ }^{\circ} \mathrm{C}$ and $70 \%$ relative humidity. When the mycelium of fungi had reached the edges of the control Petri dishes (those without essential oils), the antifungal indices were calculated. The formula of antifungal indices is shown as

Anti-wood-decay fungal index $(\%)=(1-\mathrm{Da} / \mathrm{Db}) \mathrm{X} 100$,

where $\mathrm{Da}$ is the diameter of the growth zone in the experimental dish $(\mathrm{cm})$ and $\mathrm{Db}$ is the diameter of the growth zone in the control dish (cm). DDAC (didecyl dimethyl ammonium chloride) is a wood preservative for wood decay fungi and is used as a positive control.

\section{Results and Discussion}

Hydrodistillation of $M$. zuihoensis leaves produced a yellow-colored oil with a yield of $2.68 \pm 0.05$ $\mathrm{mL} / 100 \mathrm{~g}$, based on the dry weight of leaves. One hundred and four compounds were identified (Table 1), of which oxygenated sesquiterpenes were predominant (31.1\%), followed by non-terpenoids (30.2\%), sesquiterpene hydrocarbons (21.8\%), monoterpene hydrocarbons (14.6\%), oxygenated monoterpenes $(1.9 \%)$, and diterpenes $(0.5 \%)$. Among the oxygenated sesquiterpenes, $(E)$-nerolidol $(10.5 \%), \quad \beta$-eudesmol $(5.7 \%)$, and $\tau$-cadinol (5.3\%) were the major compounds, and of the non-terpenoids, $n$-dodecanal $(23.8 \%)$ and n-decanal (5.3\%) were the chief components. Among the sesquiterpene hydrocarbons, viridiflorene (4.2\%) was the main component. This is the first study on the chemical characterization from the leaf oil.

From the results presented above, the leaf oil constituents of $M$. zuihoensis were primarily sesquiterpenoids. Intra-genus leaf oil comparisons indicated that many Machilus trees, such as $M$. kusanoi (Ho et al., 2011), M. pseudolongifolia (Ho et al., 2010a), M. philippinensis (Ho et al., 2010b), M. obovatifolia (Ho et al., 2010c), M. velutina (Zhu et al., 1994), and M. thunbergii (Komae \& Hayashi, 1972), all have predominately sesquiterpenoids as their main constituents. However, the main components of the individual species differed. Further comparison with the leaf oil of M. japonica (Van Khien et al., 2009) was predominantly monoterpenoids and, therefore, differed from the leaf oil of M. zuihoensis.

The essential oil of M. zuihoensis was tested against three Gram-positive and five Gram-negative bacteria, as well as two fungi. The results, presented in Table 2, indicated that a moderate to strong growth suppression against all ten microbes. The most sensitive microorganisms were $B$. cereus, $S$. aureus, $S$. epidermidis, and $C$. albicans with inhibition zones of 35

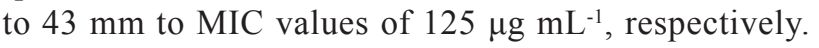
The essential oil showed superior suppressive activity toward the Gram-positive bacteria than that of either the Gram-negative bacteria or the fungi.

Table 1. Chemical composition of the leaf oil Machilus zuihoensis Hayata, Lauraceae.

\begin{tabular}{|c|c|c|c|}
\hline Constituents & $\mathrm{RI}^{\mathrm{a}}$ & Conc. $(\%)^{\mathrm{b}}$ & Identification $^{c}$ \\
\hline cis-3-hexenol & 859 & 0.1 & RI, MS, ST \\
\hline$\alpha$-pinene & 939 & 0.4 & RI, MS, ST \\
\hline camphene & 954 & 0.1 & RI, MS, ST \\
\hline benzaldehyde & 960 & td & RI, MS, ST \\
\hline trans-pinene & 975 & $\mathrm{t}$ & RI, MS \\
\hline$\beta$-pinene & 979 & $\mathrm{t}$ & RI, MS, ST \\
\hline myrcene & 991 & 0.3 & RI, MS, ST \\
\hline$\delta$-2-carene & 1002 & $\mathrm{t}$ & RI, MS, ST \\
\hline$\alpha$-phellandrene & 1003 & 2.6 & RI, MS, ST \\
\hline cis-3-hexenyl acetate & 1005 & $\mathrm{t}$ & RI, MS, ST \\
\hline iso-sylvestrene & 1009 & 0.1 & RI, MS \\
\hline$\alpha$-terpinene & 1017 & 0.5 & RI, MS, ST \\
\hline p-cymene & 1025 & 3.8 & RI, MS, ST \\
\hline$\beta$-phellandrene & 1030 & 1.0 & RI, MS, ST \\
\hline 1.8-cineole & 1031 & $\mathrm{t}$ & RI, MS, ST \\
\hline cis-ocimene & 1037 & 3.3 & RI, MS \\
\hline trans-ocimene & 1050 & 0.4 & RI, MS \\
\hline$\gamma$-terpinene & 1060 & 0.2 & RI, MS, ST \\
\hline$n$-octanol & 1068 & $\mathrm{t}$ & RI, MS, ST \\
\hline$p$-mentha-3.8-diene & 1073 & 0.1 & RI, MS \\
\hline$p$-cymenene & 1091 & 1.8 & RI, MS, ST \\
\hline linalool & 1097 & 0.1 & RI, MS, ST \\
\hline$n$-nonanal & 1101 & $\mathrm{t}$ & RI, MS, ST \\
\hline cis-p-menth-2-en-1-ol & 1122 & 0.1 & RI, MS \\
\hline allo-ocimene & 1132 & 0.1 & RI, MS \\
\hline trans-pinocarveol & 1139 & $\mathrm{t}$ & RI, MS, ST \\
\hline cis- $\beta$-terpineol & 1144 & $\mathrm{t}$ & RI, MS \\
\hline neo-3-thujanol & 1154 & $\mathrm{t}$ & RI, MS \\
\hline
\end{tabular}




\begin{tabular}{|c|c|c|c|}
\hline 3-thujanol & 1169 & $\mathrm{t}$ & RI, MS \\
\hline$n$-nonanol & 1169 & $\mathrm{t}$ & RI, MS, ST \\
\hline menthol & 1172 & $\mathrm{t}$ & RI, MS, ST \\
\hline terpinen-4-o1 & 1177 & 0.1 & RI, MS, ST \\
\hline p-cymen-8-ol & 1183 & 0.1 & RI, MS, ST \\
\hline$\alpha$-terpineol & 1189 & 1.0 & RI, MS, ST \\
\hline methyl salicylate & 1192 & $\mathrm{t}$ & RI, MS, ST \\
\hline dihydro carveol & 1194 & 0.1 & RI, MS \\
\hline$n$-decanal & 1202 & 5.3 & RI, MS, ST \\
\hline iso-dihydro carveol & 1215 & $\mathrm{t}$ & RI, MS \\
\hline trans-pulegol & 1215 & $\mathrm{t}$ & RI, MS \\
\hline neoiso-dihydro carveol & 1229 & $\mathrm{t}$ & RI, MS \\
\hline carvotanacetone & 1247 & 0.1 & RI, MS \\
\hline piperitone & 1253 & $\mathrm{t}$ & RI, MS \\
\hline isobornyl acetate & 1286 & $\mathrm{t}$ & RI, MS, ST \\
\hline 10-undecenal & 1300 & 0.1 & RI, MS, ST \\
\hline$n$-undecanal & 1307 & 0.1 & RI, MS, ST \\
\hline$\delta$-elemene & 1338 & $\mathrm{t}$ & RI, MS \\
\hline$\alpha$-cubebene & 1351 & $\mathrm{t}$ & RI, MS \\
\hline eugenol & 1359 & $\mathrm{t}$ & RI, MS, ST \\
\hline 10-undecen-1-ol & 1363 & 0.2 & RI, MS, ST \\
\hline$n$-undecanol & 1370 & 0.2 & RI, MS, ST \\
\hline isoledene & 1376 & 0.1 & RI, MS, ST \\
\hline$\alpha$-copaene & 1377 & 0.6 & RI, MS \\
\hline geranyl acetate & 1381 & 0.1 & RI, MS, ST \\
\hline trans- $\beta$-damascen & 1385 & $\mathrm{t}$ & RI, MS \\
\hline$\beta$-bourbonene & 1388 & $\mathrm{t}$ & RI, MS \\
\hline$\beta$-elemene & 1391 & 0.5 & RI, MS \\
\hline dodecanal & 1409 & 23.8 & RI, MS, ST \\
\hline$\beta$-caryophyllene & 1419 & 2.6 & RI, MS, ST \\
\hline$\beta$-copaene & 1432 & 0.1 & RI, MS \\
\hline$\beta$-gurjunene & 1434 & 0.1 & RI, MS \\
\hline$\gamma$-elemene & 1437 & 0.1 & RI, MS \\
\hline aromadendrene & 1441 & 1.3 & RI, MS, ST \\
\hline cis-prenyl limonene & 1446 & 0.3 & RI, MS \\
\hline$\alpha$-neo-clovene & 1454 & 0.2 & RI, MS \\
\hline$\alpha$-caryophyllene & 1455 & 0.8 & RI, MS \\
\hline allo-aromadendrene & 1460 & 0.2 & RI, MS, ST \\
\hline 9-epi- $\beta$-caryophyllene & 1466 & 0.3 & RI, MS \\
\hline drima-7,9(11)-diene & 1473 & 0.2 & RI, MS \\
\hline trans-cadina-1(6),4-diene & 1477 & 1.6 & RI, MS \\
\hline germacrene D & 1485 & 0.4 & RI, MS, ST \\
\hline$\beta$-selinene & 1490 & 1.2 & RI, MS \\
\hline$\delta$-selinene & 1493 & 0.5 & RI, MS \\
\hline viridiflorene & 1497 & 4.2 & RI, MS, ST \\
\hline$\alpha$-muurolene & 1500 & 1.1 & RI, MS \\
\hline$\alpha$-bulnesene & 1510 & 0.8 & RI, MS \\
\hline$\delta$-amorphene & 1512 & 0.1 & RI, MS \\
\hline
\end{tabular}

\begin{tabular}{|c|c|c|c|}
\hline$\gamma$-cadinene & 1514 & 1.0 & RI, MS \\
\hline cubebol & 1515 & 0.1 & RI, MS \\
\hline$\delta$-cadinene & 1523 & 2.1 & RI, MS \\
\hline trans-cadina-1(2),4-diene & 1535 & 0.3 & RI, MS \\
\hline$\alpha$-cadinene & 1539 & 0.9 & RI, MS \\
\hline$\alpha$-calaconene & 1546 & 0.3 & RI, MS, ST \\
\hline cis-cadinene & 1554 & 0.2 & RI, MS \\
\hline$(E)$-nerolidol & 1563 & 10.5 & RI, MS, ST \\
\hline ledol & 1569 & 0.4 & RI, MS \\
\hline caryophyllenyl alcohol & 1572 & 0.8 & RI, MS, ST \\
\hline globulol & 1585 & 1.7 & RI, MS, ST \\
\hline guaiol & 1601 & 0.8 & RI, MS, ST \\
\hline 5-epi-7-epi- $\alpha$-eudesmol & 1608 & 0.9 & RI, MS \\
\hline$n$-tetradecanal & 1613 & 0.2 & RI, MS, ST \\
\hline 1,10-di-epi-cubenol & 1619 & 0.3 & RI, MS \\
\hline 10-epi- $\gamma$-eudesmol & 1624 & 0.8 & RI, MS \\
\hline 1-epi-cubenol & 1629 & 0.4 & RI, MS \\
\hline$\gamma$-eudesmol & 1632 & 0.6 & RI, MS \\
\hline$\tau$-cadinol & 1640 & 5.3 & RI, MS, ST \\
\hline$\delta$-cadinol & 1646 & 0.5 & RI, MS \\
\hline$\beta$-eudesmol & 1651 & 5.7 & RI, MS, ST \\
\hline$\alpha$-eudesmol & 1654 & 0.2 & RI, MS \\
\hline intermedeol & 1667 & 0.2 & RI, MS \\
\hline cadalene & 1677 & 0.1 & RI, MS \\
\hline epi- $\alpha$-bisabolol & 1685 & 0.5 & RI, MS \\
\hline$\alpha$-bisabolol & 1686 & 0.3 & RI, MS \\
\hline$(2 Z, 6 E)$-farnesol & 1701 & 1.0 & RI, MS \\
\hline phytol & 1943 & 0.5 & RI, MS, ST \\
\hline \multicolumn{2}{|c|}{ Monoterpene hydrocarbons (\%) } & 14.6 & \\
\hline \multicolumn{2}{|c|}{ Oxygenated monoterpenes (\%) } & 1.9 & \\
\hline \multicolumn{2}{|c|}{ Sesquiterpene hydrocarbons (\%) } & 21.8 & \\
\hline \multicolumn{2}{|c|}{ Oxygenated sesquiterpenes (\%) } & 31.1 & \\
\hline \multicolumn{2}{|l|}{ Diterpenes (\%) } & 0.5 & \\
\hline \multicolumn{2}{|l|}{ Others $(\%)$} & 30.2 & \\
\hline \multicolumn{2}{|l|}{ Oil Yield (mL/100 g) } & $2.68 \pm 0.05$ & \\
\hline
\end{tabular}

${ }^{\text {aRetention index on a DB-5 column with reference to } n \text {-alkanes }}$ (Adams, 2001); ${ }^{b} \mathrm{n}=3$; ${ }^{\mathrm{c}} \mathrm{MS}$, NIST and Wiley library spectra and the literature; RI: Retention index; ST: authentic standard compounds; ${ }^{\mathrm{d}}$ trace $<0.1 \%$.

The probable cause of the susceptibility of Gram-positive bacteria and relative tolerance of Gram-negative bacteria to essential oils has been correlated with the presence of a hydrophilic outer layer (Kalemba \& Kunicka, 2003). It is presumed that penetration of hydrophobic components in Gramnegative microorganisms is more difficult due to the presence of a second physical barrier formed by the outer membrane (Mann et al., 2000; Duffy \& Power, 2001). Comparing the antimicrobial activities of the 
leaf essential oils with that extracted from M. kusanoi (Ho et al., 2011), M. pseudolongifolia (Ho et al., 2010a), and Litsea linii (Ho et al., 2010d), and the twig oil with that extracted from L. mushaensis (Ho et al., 2010d), the leaf essential oil of M. zuihoensis was superior (Table 3 ). The results verify that $M$. zuihoensis leaf oil has excellent antimicrobial activity. However, to ascertain the source compounds of antimicrobial activity from $M$. zuihoensis, the main components were individually tested for antimicrobial activities. The results indicated that the active source compounds were $\tau$-cadinol, $\beta$-eudesmol and $n$-dodecanal. These results were similar to those of Ho et al. (2010d; 2011). There are also studies that have supported the contention that these compounds have high activity in suppressing microbial growth (Kondo \& Imamura, 1986; Knobloch et al., 1989; Kalemba \& Kunicka, 2003; Kusuma et al., 2004).

Table 2. Antimicrobial activity of the leaf essential oil of Machilus zuihoensis.

\begin{tabular}{|c|c|c|c|c|c|c|c|c|c|c|c|}
\hline \multirow{3}{*}{ Microbial species } & \multirow{2}{*}{\multicolumn{2}{|c|}{$\frac{\text { M. zuihoensis }}{\text { Leaf }}$}} & \multicolumn{6}{|c|}{ Compounds $^{c}$} & \multicolumn{3}{|c|}{ Antibiotics } \\
\hline & & & \multirow{2}{*}{$\begin{array}{c}1 \\
\mathrm{MIC}\end{array}$} & \multirow{2}{*}{$\begin{array}{c}2 \\
\mathrm{MIC}\end{array}$} & \multirow{2}{*}{$\begin{array}{c}3 \\
\mathrm{MIC}\end{array}$} & \multirow{2}{*}{$\begin{array}{c}4 \\
\mathrm{MIC}\end{array}$} & \multirow{2}{*}{$\begin{array}{c}5 \\
\mathrm{MIC}\end{array}$} & \multirow{2}{*}{$\begin{array}{c}6 \\
\mathrm{MIC}\end{array}$} & \multirow{2}{*}{$\begin{array}{c}\begin{array}{c}\text { Tetracycline } \\
(30 \mu \mathrm{g} / \text { disk })\end{array} \\
\mathrm{IZ}\end{array}$} & \multirow{2}{*}{$\begin{array}{c}\begin{array}{c}\text { Gentamicine } \\
(10 \mu \mathrm{g} / \text { disk })\end{array} \\
\mathrm{IZ}\end{array}$} & \multirow{2}{*}{$\begin{array}{c}\begin{array}{c}\text { Nystatine } \\
(30 \mu \mathrm{g} / \text { disk })\end{array} \\
\mathrm{IZ}\end{array}$} \\
\hline & $\mathrm{IZ}^{\mathrm{a}}$ & $\mathrm{MIC}^{\mathrm{b}}$ & & & & & & & & & \\
\hline Bacillus cereus & $36 \pm 0.4$ & 125 & $>1000$ & 250 & $>1000$ & 250 & 62.5 & 125 & $22 \pm 0.8$ & - & $\mathrm{nt}$ \\
\hline Staphylococcus aureus & $43 \pm 0.4$ & 125 & 1000 & 125 & 1000 & 250 & 62.5 & 62.5 & $21 \pm 0.4$ & - & $\mathrm{nt}$ \\
\hline Staphylococcus epidermidis & $42 \pm 0.8$ & 125 & 1000 & 125 & 1000 & 250 & 62.5 & 62.5 & $34 \pm 0.4$ & - & $\mathrm{nt}$ \\
\hline Escherichia coli & $25 \pm 0.8$ & 500 & $>1000$ & 500 & $>1000$ & 1000 & 500 & 500 & $-d$ & $22 \pm 0.8$ & $\mathrm{nt}$ \\
\hline Enterobacter aerogenes & $30 \pm 0.4$ & 375 & $>1000$ & 250 & $>1000$ & 500 & 125 & 125 & $10 \pm 0.4$ & - & nt \\
\hline Klebsiella pneumoniae & $29 \pm 0.4$ & 375 & $>1000$ & 250 & $>1000$ & 500 & 125 & 125 & - & $21 \pm 0.8$ & nt \\
\hline Pseudomonas aeruginosa & $25 \pm 0.8$ & 500 & $>1000$ & 750 & $>1000$ & 1000 & 500 & 500 & - & $12 \pm 0.8$ & $\mathrm{nt}$ \\
\hline Vibrio parahaemolyticus & $19 \pm 0.4$ & 1000 & $>1000$ & 1000 & $>1000$ & & 1000 & 1000 & - & $13 \pm 0.8$ & nt \\
\hline
\end{tabular}

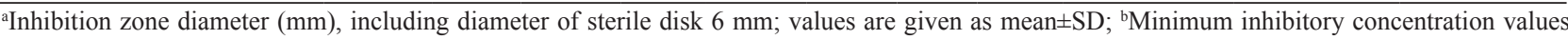
as $\mu \mathrm{g} \mathrm{mL}^{-1}$; ${ }^{\mathrm{c}} 1$. $n$-decanal $(\geq 98 \%), 2 . n$-dodecanal $(\geq 98 \%), 3$. viridiflorene $(\geq 98 \%), 4$. (E)-nerolidol $(\geq 98.5 \%), 5 . \tau$-cadinol $(100 \%), 6$. $\beta$-eudesmol $(\geq 98 \%$ ). Compound 1 to 4 were purchased from the Fluka Co. (Milwaukee, USA), and Compound 6 was purchased from the Wako Co. (Tokyo, Japan), where as the Compound 5 was from isolate of the Ho et al. (2010b) study on Machilus philippinenesis essential oil; Essential oil tested at $15 \mu \mathrm{L} /$ disc for bacteria and $30 \mu \mathrm{L} /$ disc for fungi; ${ }^{(-)}$, Inactive; ent, not tested.

Table 3. Comparison of the MIC values $\left(\mu \mathrm{g} \mathrm{mL}^{-1}\right.$ ) of the oils of M. zuihoensis and those of M. kusanoi, M. pseudolongifolia, Litsea linii and L. mushaensis against the microbial.

\begin{tabular}{|c|c|c|c|c|c|c|c|c|c|c|c|c|}
\hline & \multirow{2}{*}{ Essential oil } & \multicolumn{10}{|c|}{ Microbial * } & \multirow{2}{*}{ Reference } \\
\hline & & B. c. & S. $a$. & S.e. & E. c. & E. $a$. & $K . p$. & P. $a$. & $V \cdot p$. & A. $n$. & C. $a$. & \\
\hline \multicolumn{13}{|l|}{ Leaf } \\
\hline & Machilus zuihoensis & 125 & 125 & 125 & 500 & 375 & 375 & 500 & 1000 & 1000 & 125 & This study \\
\hline & M. kusanoi & 250 & 125 & 125 & 500 & 375 & 375 & 500 & 1000 & 1000 & 250 & Ho et al., 2011 \\
\hline & M. pseudolongifolia & 250 & 125 & 125 & 750 & 375 & 375 & 750 & 1000 & $>1000$ & 250 & Ho et al., 2010a \\
\hline & Litsea linii & 500 & 500 & 500 & 750 & 750 & $>1000$ & $>1000$ & $>1000$ & $>1000$ & 750 & Ho et al., 2010d \\
\hline \multicolumn{13}{|l|}{ Twig } \\
\hline & L. mushaensis & 1000 & 750 & 750 & $>1000$ & $>1000$ & $>1000$ & $>1000$ & $>1000$ & $>1000$ & $>1000$ & Ho et al., 2010d \\
\hline
\end{tabular}

Table 4. Anti-wood-decay fungal indices of leaf essential oil from Machilus zuihoensis.

\begin{tabular}{ccccc}
\hline \multirow{2}{*}{$\begin{array}{c}\text { Dosage } \\
\left(\mu \mathrm{g} \mathrm{mL} \mathrm{mL}^{-1}\right)\end{array}$} & $\begin{array}{c}\text { Trametes } \\
\text { versicolor }\end{array}$ & $\begin{array}{c}\text { Phaneochaete } \\
\text { chrysosporium }\end{array}$ & $\begin{array}{c}\text { Phaeolus } \\
\text { schweintizii }\end{array}$ & $\begin{array}{c}\text { Lenzites } \\
\text { sulphureu }\end{array}$ \\
\hline 12.5 & $35 \pm 3.3$ & $25 \pm 3.3$ & $38 \pm 3.3$ & $68 \pm 3.3$ \\
25.0 & $62 \pm 3.3$ & $50 \pm 3.3$ & $80 \pm 3.3$ & $100 \pm 0.0$ \\
50.0 & $90 \pm 6.6$ & $88 \pm 6.6$ & $100 \pm 0.0$ & $100 \pm 0.0$ \\
75.0 & $100 \pm 0.0$ & $100 \pm 0.0$ & $100 \pm 0.0$ & $100 \pm 0.0$ \\
100.0 & $100 \pm 0.0$ & $100 \pm 0.0$ & $100 \pm 0.0$ & $100 \pm 0.0$ \\
\hline${ }^{n}=3$. & & & &
\end{tabular}

Table 5. Comparison of the MIC values $\left(\mu \mathrm{g} \mathrm{mL} \mathrm{m}^{-1}\right)$ of the leaf oils of Machilus zuihoensis and those of M. pseudolongifolia, $M$. philippinensis and M. kusanoi against the wood-decay fungi.

\begin{tabular}{lccccc}
\hline \multirow{2}{*}{ Essential oil } & \multicolumn{4}{c}{ Fungi * } & Reference \\
\cline { 2 - 5 } & T. v. & Phane. c. & Phaeo. s. & L. s. & \\
\hline Machilus zuihoensis & 75 & 75 & 50 & 25 & This study \\
M. pseudolongifolia & 75 & 75 & 75 & 25 & Ho et al., 2010a \\
M. philippinensis & 100 & 100 & 100 & 50 & Ho et al., 2010b \\
M. kusanoi & 75 & 75 & 75 & 25 & Ho et al., 2011 \\
\hline * T. v.: Trametes versicolor; & Phane. & c.: & Phaneochaete chrysosporium;
\end{tabular}

Phaeo. s: Phaeolus schweintizii; L. s.: Lenzites sulphureu 


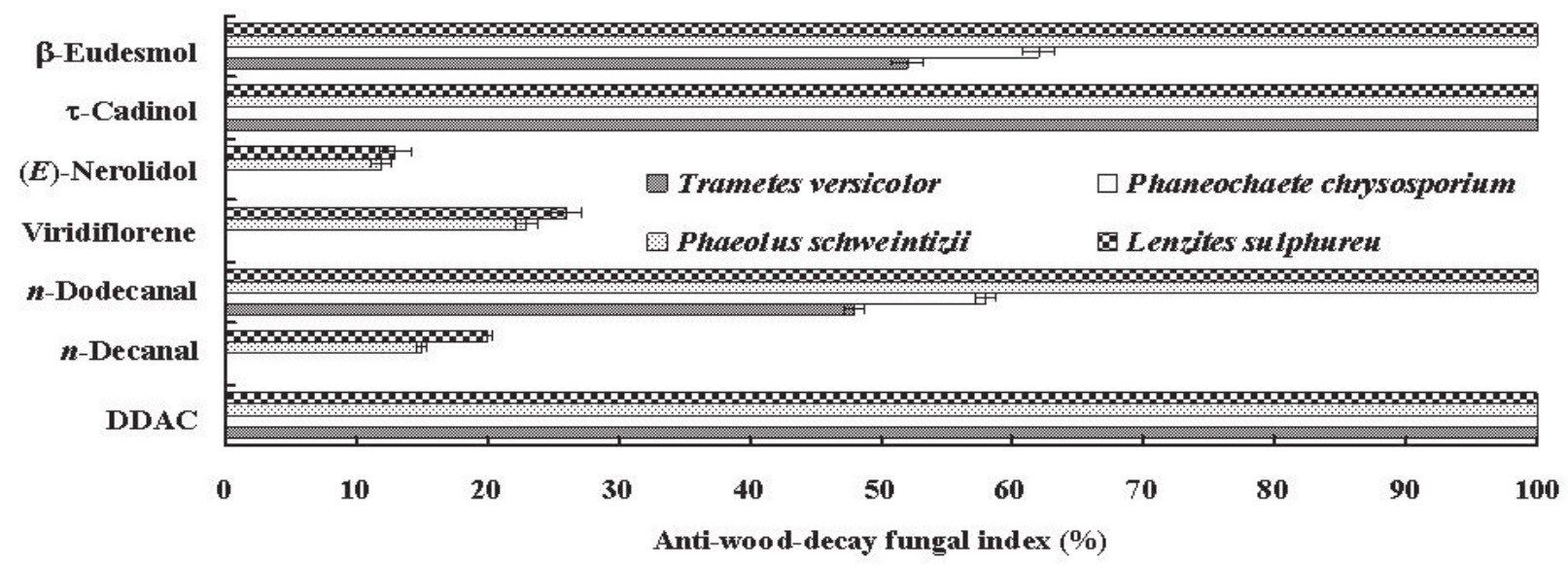

Figure 1. Anti-wood-decay fungal indices of the six main compounds $\left(50 \mu \mathrm{g} \mathrm{mL}^{-1}\right)$ of the leaf essential oil of $M$. zuihoensis (Note: DDAC (didecyl dimethyl ammonium chloride) is a wood preservative for wood decay fungi and is used as a positive control).

The essential oil of $M$. zuihoensis was tested against two white rot fungi ( $T$. versicolor and Phane. chrysosporium) and two brown rot fungi (Phaeo. schweinitzii, L. sulphureus). The anti-wooddecay fungal indices presented in Table 4 are a clear demonstration of the excellent anti-wood-decay fungal property of the oil. The growth of T. versicolor, Phane. chrysosporium, Phaeo. schweintizii, and L. sulphureu was completely inhibited at concentrations of 100, 100, $50,25 \mu \mathrm{g} \mathrm{mL}^{-1}$, respectively.

Comparing the anti-wood-decay fungal activities of the essential oils from Machilus spp. such as M. pseudolongifolia (Ho et al., 2010a), M. philippinensis (Ho et al., 2010b) and M. kusanoi (Ho et al., 2011), the leaf oil of M. zuihoensis was superior (Table 5). The results verified that M. zuihoensis leaf oil has excellent anti-wood-decay fungal activities.

Furthermore, to ascertain the source compounds of the M. zuihoensis essential oil, we also tested the antiwood decay fungal activities of its major component compounds (Figure 1). The results indicated that the sources of activities were also $\tau$-cadinol, $\beta$-eudesmol, and n-dodecanal. The IC50 values of the three compounds ( $\tau$-cadinol, $\beta$-eudesmol, and $n$-dodecanal) against the four decay fungi were $36.8,48.1$, and $56.5 \mu \mathrm{g} \mathrm{mL}^{-1}$ against $T$. versicolor; 13.5, 38.2, and $42.6 \mu \mathrm{g} \mathrm{mL}^{-1}$ against Phane. chrysosporium; 28.9, 23.1, and $25.3 \mu \mathrm{g} \mathrm{mL}^{-1}$ against $P$ haeo. Shweinitzii; and 23.3, 20.6, and $23.2 \mu \mathrm{g} \mathrm{mL}-1$ against L.

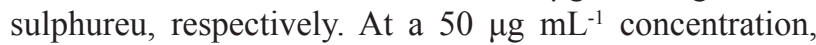
$\tau$-cadinol showed total growth inhibition against all whiterot and brown-rot fungi tested, while $n$-dodecanal and $\beta$-eudesmol could completely inhibit brown-rot fungi but partially inhibit white-rot fungi. The results correspond with those of Kondo \& Imamura (1986), Mori et al. (2000), Nami et al. (2006), Ho et al. (2010b) and Ho et al. (2011).
Thus, the excellent wood-decay fungi inhibitive activities exhibited by the $M$. zuihoensis leaf oil may be attributed to the presence of compounds such as $\tau$-cadinol, $\beta$-eudesmol, and $n$-dodecanal.

\section{References}

Adams RP 2001. Identification of Essential Oil Components by Gas Chromatography/Quadruple Mass Spectroscopy. Illinois: Allured Publishing Corporation.

Baron EJ, Finegold SM 1990. Methods for testing antimicrobial effectiveness. In Stephanie M (Ed.) Diagnostic Microbiology. Baltimore: Mosby Press, p.171-194.

Cheng SS, Lin HY, Chang ST 2005. Chemical composition and antifungal activity of essential oils from different tissues of Japanese cedar (Cyptomeria japonica). $J$ Agric Food Chem 53: 614-619.

Duffy CF, Power RF 2001. Antioxidant and antimicrobial properties of some Chinese plant extracts. Int $J$ Antimicrob Agents 17: 527-529.

Ho CL, Liao PC, Hsu KP, Wang EIC, Dong WC, Su YC 2010a. Composition and antimicrobial and anti-wood-decay fungal activities of the leaf essential oils of Machilus pseudolongifolia from Taiwan. Nat Prod Commun 5: 1143-1146.

Ho CL, Hsu KP, Wang EIC, Lin CY, Su YC 2010 b. Composition and anti-wood-decay fungal activities of the leaf essential oil of Machilus philippinensis from Taiwan. Nat Prod Commun 5: 337-340.

Ho CL, Hsu KP, Wang EIC, Lin CY, Su YC 2010c. Composition and antimicrobial activity of the leaf essential oil of Machilus obovatifolia From Taiwan. J Essen Oil Res 21: 471-475.

Ho CL, Wang EIC, Tseng YH, Liao PC, Lin CN, Chou JC, Su 
YC 2010d. Composition and antimicrobial activity of the leaf and twig oils of Litsea mushaensis and L. linii from Taiwan. Nat Prod Commun 5: 1823-1828.

Ho CL, Hsu KP, Tseng YH, Wang EIC, Liao PC, Chou JC, Lin CN, Su YC 2011. Composition and antimicrobial activities of the leaf essential oils of Machilus kusanoi from Taiwan. Nat Prod Commun 6: 267-270.

Kalemba D, Kunicka A 2003. Antibacterial and antifungal properties of essential oils. Curr Med Chem 10: 813829.

Kartal SN, Imamura Y, Tsuchiya F, Ohsato K 2004a. Evaluation of fungicidal and termiticidal activities of hydrolysates from biomass slurry fuel production from wood. Bioresour Technol 95: 41-47.

Kartal SN, Dorau BF, Lebow ST, Grenn IF 2004b. Effects of inorganic ions on leachability of wood preserving $N, N$-hydroxynapthalimide (NHA). Forest Product $J$ 54: 80-84.

Knobloch K, Pauli A, Lberl B, Weigand H, Weis N 1989. Antibacterial and antifungal properties of essential oil components. J Essen. Oil Res 1: 119-128.

Komae H, Hayashi N 1972. Terpenes from Actinodaphne, Machilus and Neolitsea species. Phytochemistry 11: 1181-1182.

Kondo R, Imamura H 1986. Antifungal compounds in heartwood extractives of hinoki (Chamaecyparis obtuse Endl.). J Jap Wood Res Soc, 32: 213-217.

Kusuma IW, Ogawa T, Itoh K, Tachibana S 2004. Isolation and identification of an antifungal sesquiterpene alcohol from Amboyna wood. Pakistan J Biol Sci 7: 1735-1740.

Liao JC 1996. Lauraceae in flora of Taiwan. Taipei, Taiwan: Editorial Committee of the Flora of Taiwan.

Mann CM, Cox SD, Markham JL 2000. The outer membrane of Pseudomonas aeruginosa NCTC6749 contributes to its tolerance to the essential oil of Melaleuca alternifolia (tea tree oil). Lett Appl Microbiol 30: 294297.

Massada Y 1976. Analysis of Essential Oil by Gas Chromatography and Spectrometry. Wiley: New York.

Mori M, Aoyama M, Doi S 2000. Antifungal constituents in the bark of Magnolia obovata Thunb. J Hokkaido Forest Prod Res Inst 14: 1-5.

Nami KS, Hwang WJ, Imamura Y, Sekine Y 2006. Effect of essential oil compounds and plant extracts on decay and termite resistance of wood. Holz Roh Werkst 64: 455-461.

NCCLS (National Committee for Clinical Laboratory Standards) 1999. Performance standards for antimicrobial susceptibility testing; $9^{\text {th }}$ International Supplement, Wayne PA., M100-S9.

Van Khien P, Do Huy Q, Do Huong TV 2009. Chemical composition of essential oil of Machilus japonica Siebold \& Zucc. (Lauraceae) from Vietnam. $V N U J$ Sci, Nat Sci Technol 25: 81-83.

Zhu LF, Li YH, Li BL, Lu BY, Xia NH 1994. Aromatic Plants and Essential Constituents. South China Institute of Botany, Chinese Academy of Science, Hai Feng: Hong Kong.

\section{*Correspondence}

\section{Yu-Chang Su}

Department of Forestry, National Chung Hsing University, 250 Kuo Kuang Rd., Taichung, Taiwan 402

ycsu@nchu.edu.tw

Tel. +886-4-22851314

Fax: +886-4-22851314 